\title{
A Review of the Flammability Factors of Kenaf and Allied Fibre Reinforced Polymer Composites
}

\author{
C. H. Lee, Mohd Sapuan Salit, and M. R. Hassan \\ Department of Mechanical and Manufacturing Engineering, Universiti Putra Malaysia (UPM), 43400 Serdang, Selangor, Malaysia \\ Correspondence should be addressed to Mohd Sapuan Salit; drsapuan@yahoo.com
}

Received 25 September 2013; Accepted 27 January 2014; Published 15 April 2014

Academic Editor: Md Enamul Hoque

Copyright (C) 2014 C. H. Lee et al. This is an open access article distributed under the Creative Commons Attribution License, which permits unrestricted use, distribution, and reproduction in any medium, provided the original work is properly cited.

\begin{abstract}
Natural fibre is a well-known reinforcement fibre in polymer-matrix Composites (PMC) lately. Natural fibre has fast growing and abundance properties which make it available at very low cost. For kenaf fibre there is long lists of research projects which have been done regarding its behaviour, and properties and modification made to it. In this paper, fire flammability is the main concern for natural fibre reinforced polymer (NFRP) composites especially kenaf fibre. To estimate its flammability, a wide range of factors can be considered such as fibre content, type of matrices, $\mathrm{pH}$ conditions, treatment, and fire retardant (FR) filler's type. The most important criteria are the ignition time, rate of propagation, and fire behavior. thermogravimetric analysis (TGA), different scanning calorimetric (DSC), and dynamic mechanical analysis (DMA) are the three most famous methods used to investigate the fire behaviour of composites.
\end{abstract}

\section{Introduction}

In the USA, in-flight smoke events happened once a day [1]. Fortunately, they have a very low probability of becoming uncontrolled in-flight fires. Aircraft accidents are often accompanied by fire, but smoke is actually the main threat to passengers. Chaturvedi et al. [2] have shown that more than $41 \%$ of fatalities are caused by fire and smoke in an aircraft crash. In-flight fire accidents constitute one of the top four leading fatalities besides loss of control, controlled flight into terrain, and specific component failure [3]. 423 fatalities are accounted for 18 major in-flight fire accidents from 1990 to 2010 [4].

Aircraft cabin fires are generally grouped in ramp fires, in-flight fires, or postcrash fires. Ramp fires usually do not threaten life because they occur when the aircraft is landed and parked. Therefore, the escaping timing can be extended to more than an hour. In-flight fires are normally detected at the beginning of the fire and can be successfully extinguished. Yet they have some probability of becoming uncontrolled fires. Postcrash fires are the most severe cases. This scenario usually starts when landing [5].
In 2010, a tragic postcrash fire occurred and 158 passengers died. An Air India Express Boeing 737-800 accidentally crashed when it landing in pre-monsoon rains and then plunged into the jungle [6]. The plane was broken into two immediately and burst into flames. Low visibility caused by two days of continuous rain and the surrounding by hills made rescue work harder.

A survivor, who described the incident, said he heard a loud bang and the plane caught fire. After a while, the cabin was filled with smoke hence visibility and oxygen levels were very low. The survivor escaped by jumping out of the opening where the plane had cracked. Only eight passengers have saved themselves in this incident.

The most potential fire source is electrical. There will start a fire from smoke or fume. Two thirds of smoke event on Boeings from year 1992 until year 2000 were caused by electrical (64\%) [7]. In a modern aircraft, there is over $150 \mathrm{~km}$ of wire; any single point of wiring fault might cause an uncontrolled fire [8]. Increasing the thickness of the wire insulation does help to prevent short-circuiting of the wires. However, it adds weight to the aircraft. Therefore manufacturers are keen to find lighter insulation materials. 


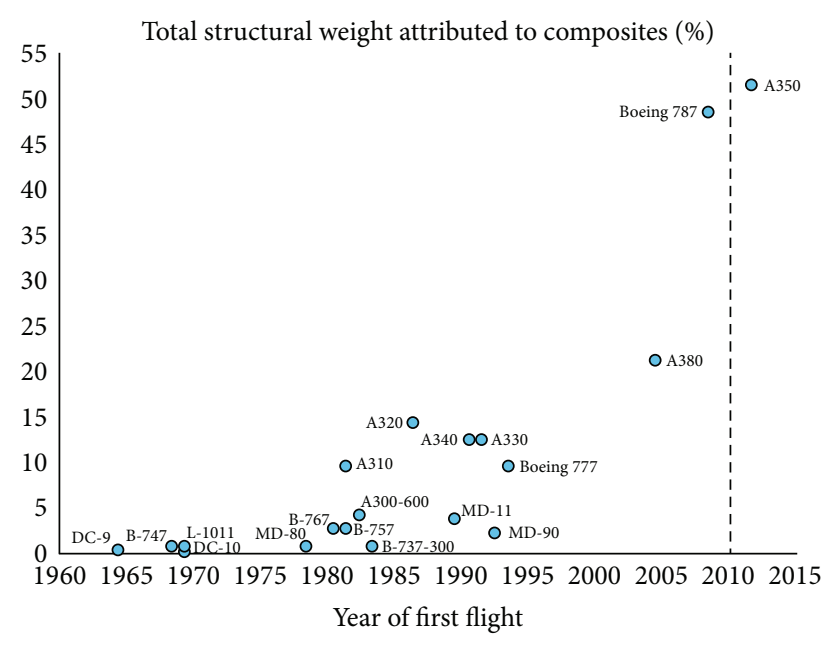

- - Anticipated

FIGURE 1: The percentage of composite materials used in an aircraft [57].

Maintenance is very important to ensure a safe environment on an aircraft. When the aircraft is old, some of the black sticky debris adheres to the wires, which is flammable. When small sparks land on this aging wiring, fast and uncontrollable fire occurs.

Figure 1 shows the percentage of composite materials used in an aircraft; it demonstrates increasingly higher percentages of structural weight being replaced with lighter yet more combustible composites material. Therefore understanding the flammability of natural fibre based polymer composites could modify its fire behaviour thus allowing passengers more time to escape from an incident. Besides this, the combustion of biocomposites produces fewer toxic gases compared to conventional composites.

\section{Natural Fibre}

As the world's technologies become more advanced, scientists are designing their inventions based on eco-environmental aspects. Researchers have noticed that some of the conventional products do not currently fulfill these requirements. Therefore conventional engineering fibres such as glass and carbon fibres, gradually substituted by natural fibre and sometimes use along with mineral fillers to meet the specification of certain task [9]. These engineered fibres are being produced with uniform properties in every single fibre in terms of dimensions and mechanical properties [10]. However, they are being abandoned because of the environmental and health issues created. As a substitute, there is an exponential growth of interest in using natural fibres. Fibre crops are not a new product for humans. Most of the natural fibres were implemented in daily life in Egypt from about 7,000 years ago [11]. Even humans in the Stone Age combined some short length fibres and twisted them together as cords and yarns [12].
Many studies have been done around the world in an attempt to prove that natural fibre based composites are capable of replacing synthetic engineered fibres. Davoodi et al. [13] replaced a car bumper beam with a hybrid kenaf/glass reinforced epoxy composite to reduce the environmental issue, yet retain the required strength. Besides this, kenaf fibre is being used to produce paper to avoid the deforestation problem. The papers made are stronger, whiter, of higher duration for yellowing resistance, and smoother for printing [14-16].

Dye compounds have been in popular use in many fields, such as textiles, cosmetics, and papers. Expelling the wastewater containing dye compounds into clean water will dissolve the oxygen content in the water and prohibit sunrays passing through the water as well. The high moisture adsorption of the natural fibre allowed the absorption of the pigment in the waste water [17]. Higher flame resistances of particleboard made by flame retardant-treated kenaf fibre have been published compared to conventional particleboard [18]. Despite this, lumens of natural fibre are excellent acoustic proofing for particleboard $[19,20]$.

2.1. Kenaf Fibre. Conventional and traditional fibre reinforced composites can be made using carbon fibres or glass fibres inserted into unsaturated polyester or epoxy resins. These composites bring us about high mechanical and thermal properties which are the main characteristic required in various applications from aerospace to sport uses. However, these advantages come along with environmental issues. Therefore, composites made up from natural fibre as reinforcement, combined with biodegradable polymer matrices, are the best solution for the environmental issues yet still retain the required strength and properties.

Kenaf is one of the most well-known natural fibres to be used as reinforcement in PMC. Kenaf is also known as Hibiscus cannabinus L. It is an herbaceous annual plant that can be grown under a wide range of weather conditions and produces more than $3 \mathrm{~m}$ within 3 months even in moderate ambient conditions [21]. The highest growing rate may be up to $10 \mathrm{~cm} /$ day. However, different environments will still yield various heights of kenaf plant, such as the cultivar, planting date, photosensitivity, length of growing season, plant populations, and plant maturity. The stem of the kenaf is straight and there is no branching along the stem. It is built up of an outer layer of bark and a core. Therefore, easy separation of stem can be done either by chemicals or enzymatic retting. The bark contributes $30-40 \%$ of the dry weight for the stem and shows a dense structure. The core is a wood-like structure that makes up the remaining $60-70 \%$ of the weight. The core shows an isotropic and almost amorphous pattern, while the bark has an oriented high crystalline fibre pattern [22]. Long bast fibre types are used to make high-grade pulps for the pulp and paper industry, composite boards, or textiles. On the other hand, animal bedding, sorbents, and horticultural mixes use short core fibres [23].

Rouison et al. [24] revealed that kenaf has been actively cultivated in recent years for two main reasons. One is that kenaf absorbs the nitrogen and phosphorus that are present 
TABLE 1: Flame classification [27].

\begin{tabular}{lccccc}
\hline \multirow{2}{*}{ Classification } & \multicolumn{2}{c}{ Spread of flame at 1.5 mins } & \multicolumn{3}{c}{ Final spread of flame } \\
& Limit $(\mathrm{mm})$ & Limit for one specimen $(\mathrm{mm})$ & Limit $(\mathrm{mm})$ & Limit for one specimen $(\mathrm{mm})$ & Very low rate \\
\hline Class 1 & 165 & $165+25$ & 165 & $455+25$ & Low rate \\
Class 2 & 215 & $215+25$ & 455 & $710+75$ & Medium rate \\
Class 3 & 265 & $265+25$ & 710 & Rapid rate \\
Class 4 & & Exceeding the limits for class 3 & & \\
\hline
\end{tabular}

in the soil. These minerals also help to increase cumulative weed weight, crop height, stem diameter, and fibre yield [25]. Researchers Kuchinda et al. have determined that nitrogen application at $90 \mathrm{kgN} /$ ha has significant effect for plant growing. The other reason is that kenaf transforms carbon dioxide to oxygen at a significantly higher rate. The photosynthesis rate of kenaf is much higher than the photosynthesis rate of conventional trees [21]. The photosynthesis rate of kenaf is $23.4 \mathrm{mg} \mathrm{CO} / \mathrm{dm}^{2} / \mathrm{h}$ as compared to conventional trees of $8.7 \mathrm{mg} \mathrm{CO} 2 / \mathrm{dm}^{2} / \mathrm{h}$ under $1000 \mu \mathrm{mol} / \mathrm{cm}^{2} / \mathrm{s}$ [26]. This means that the kenaf plant is environmentally friendly not only in terms of its biodegradability, but in the fact that it also produces a lot of oxygen as well as reducing carbon dioxide.

\section{Flammability Factor of Natural Fibre Reinforced Polymer Composites}

Natural fibre composites are subject to thermal decomposition when exposeding to fire or high-intensity heat sources. Eliminating the ignition of a fire is the first priority, but the least we can do is to extend its ignition time. The ignition time widely depends on the heat intensity, the oxygen density, and the air flow in that particular area. When the fire is somehow ignited, work has to be done to reduce the fire propagation rate. The rate of fire spread is tested by fire propagation test [27]. Fire propagation capabilities depend on the total heat liberated and the fire spread for a fuel $[27,28]$. Heat emerges as a result of the chemical reactions of the combustion process. The rate of fire propagation determines the flame classification of the materials that spread across the surface. It can be categorized into four groups (as in Table 1) according to BS476: part 7: 1971.

Lastly, to inspect a fire, several methods were used: Thermo Gravimetric Analysis (TGA), Different Scanning Calorimetric (DSC), and Dynamic Mechanical Analysis (DMA). TGA allowed the determination of the mass of sample lost according to temperature [29]. The thermal decomposition of a natural fibre always started by low temperature of hemicelluloses decomposition and is followed by a sudden drop of mass caused by the pyrolysis of cellulosic. Lignin decomposition is the last component in decomposition at the highest temperature. Fire causes substances to rupture. Everything in the fire will eventually become charcoal, gases, and heat. The matrix of the composite will melt away, and the fibre is under thermal decomposition as well. This phenomenon leads to a reduction of the product's strength. The DMA program observed the time-dependent deformation behavior $x(t)$ under periodic with very small amplitude $F(t)$. It is possible to gather information such as Young's modulus/storage modulus, $E^{\prime}$, loss of modulus, $E^{\prime \prime}$ and mechanical loss factor, and $\tan \delta$, as a function of deformation [30]. Meanwhile, the DSC could determine some important parameters, such as oxidation, glass transition temperature $\left(T_{g}\right)$, crystalline level, and melting temperature [31].

Natural fibre consists of celluloses, hemicelluloses, and lignin as do wood. Thus it is as highly flammable as wood and hence its content portion will affect the flammability of composites. Besides this, different types of polymers with different characteristics will cause the composites to have different fire behavior.

In general, the implementation of FR filler into flammable materials such as natural-based polymer composites does increase the fire behavior of the sample. Chemical compounds are the most commonly used FR fillers. They usually come in the form of a powder and contain 5 to $10 \%$ of it inside the sample. Last but not least, the particle size is the main factor which influences its efficiency, due to the large surface area of the fine particle. Nanocomposite is the new area able to create high flame retardancy while withstanding a high load [32]. It is not discussed in this review due to its newness which means there is a lack of research information on the natural fibre reinforced in nanocomposites. It is believed that more studies will focus on this area in the future.

3.1. Factor of Fibre Contents. A previous study of TGA behaviour for kenaf fibre reinforced thermoplastic polyurethane (TPU) composites was carried out by El-Shekeil et al. [33]. Different kenaf fibre loadings samples were fabricated by compression moulding from $20 \%$ to $50 \%$. The first mass losing at a low temperature in all sample are due to expelling the moisture. The main temperature peak for pure TPU is around $363^{\circ} \mathrm{C}$ and is caused by polymerization. In the outcome, fibre contents were inversely proportional to the thermal stability. However, TPU/kenaf composites have lost about $80 \%$ of its weight but pure TPU have lost more than $90 \%$ of total weight. The first peak of thermal degradation for $20 \%$ kenaf fibre loading is $246^{\circ} \mathrm{C}$ and this shifted to around $217^{\circ} \mathrm{C}$ for $50 \%$ fibre content. This is because the thermal behaviour of kenaf fibre takes priority as increasing its content. The first peak of mass drop for kenaf fibre is hemicelluloses degradation and this begins at around $200^{\circ} \mathrm{C}$ [34].

John et al. [35] conducted an experiment regarding the effect of kenaf fibre content on composites when in a fire. The composites were prepared from nonwoven kenaf and 
TABLE 2: Limiting oxygen index (LOI) and heat release rate (HRR) of some polymers [58].

\begin{tabular}{lcc}
\hline Polymer & LOI & $\begin{array}{c}\text { HRR }\left(\mathrm{kW} / \mathrm{m}^{2}\right) \\
\left.\text { (Heat flux } 40 \mathrm{~kW} / \mathrm{m}^{2}\right)\end{array}$ \\
\hline Polypropylene & 18 & 1509 \\
Polyethylene & 18 & 1408 \\
Polystyrene & 18 & 1101 \\
Poly(methyl methacrylate) & 18 & 665 \\
Polycarbonate & 27 & 429 \\
Poly(vinyl chloride) & 42 & 1755 \\
\hline
\end{tabular}

polypropylene (PP) by varying the fibre content from $0 \%$ to $40 \%$. The results showed that $E^{\prime}$ increases by adding kenaf content at all temperatures. This is because of the increase of stiffness of the composite. Besides this, there are increases of $E^{\prime \prime}$ when the kenaf content is getting higher. Researchers believe this is caused by an increase in the energy absorption due to the additional kenaf fibres.

In Julkapli and Akil's [29] research, they performed a DSC analysis twice on kenaf-filled chitosan composites. The first cycle is below $100^{\circ} \mathrm{C}$, while the second cycle is below $200^{\circ} \mathrm{C}$. The reason for performing the first cycle is to eliminate the moisture content and thermal stress in the composites because the result is highly affected by water in sample [36]. One result which was the same as that of other researchers is that the fibre content increased the crystalline degree of the sample. At the same time, increasing the kenaf quantity led to a drop of $\Delta H_{f}$ value.

3.2. Factor of Matrixes. The ordinary polymer matrixes are thermo-set, thermoplastic or biopolymer. To select a polymer, the Limiting Oxygen Index (LOI) is the prime consideration. LOI is the elementary density of oxygen in a percentage that supports the combustion of a polymer. Table 2 presents the LOI and heat release rate (HRR) for certain polymers. PP is a matrix material that always leads the others and its flammability is widely studied [37-40]. A measurement of HRR for a PP matrix with four natural fibres reinforced combinations was conducted by Kozłowski and WładykaPrzybylak [41]. Although the presence of the natural fibre brought an earlier ignition, the heat released by natural fibre composites was noticeably reduced by more than $50 \%$ of the pure PP matrix.

Russo et al. [42] conducted an experiment pointing to several polymers as a matrix for kenaf fibre. The candidates used in the research are completely biodegradable poly(3hyroxybutyrate-co-3-ohydroxyvalerate) (PHBV), random copolyester of poly(butylenes adipate-co-terephthalate) (PBAT), and low-density polyethylene (LDPE). All results show that the kenaf natural fibre shifts the onset thermal degradation temperature a little bit to the left for all matrices with the same fibre content. The real judgment for the degradation temperature is the polymer matrixes themselves. However, the degradation temperature of the polymer is much higher than natural fibres, for example, LDPE reinforced with kenaf fibre in the experiment. The first
TABLE 3: Thermal behavior of kenaf/PLA composites [49].

\begin{tabular}{lcccc}
\hline Sample & $T_{g}\left({ }^{\circ} \mathrm{C}\right)$ & $T_{m}\left({ }^{\circ} \mathrm{C}\right)$ & $\Delta H_{f}(\mathrm{~J} / \mathrm{g})$ & $X_{c}(\%)$ \\
\hline PLA & 60.0 & 160.3 & - & - \\
Kenaf/PLA & 56.9 & 164.2 & 19.2 & 20.5 \\
Kenaf/PLA (1\% SCA) & 58.7 & 168.6 & 22.8 & 24.3 \\
Kenaf/PLA (3\% SCA) & 59.3 & 168.1 & 23.1 & 24.6 \\
Kenaf/PLA (5\% SCA) & 59.1 & 167.3 & 23.3 & 24.9 \\
\hline
\end{tabular}

thermal degradation will follow the degradation temperature of kenaf fibre at $350^{\circ} \mathrm{C}$ as loss of weight is the weight of the fibre content. Therefore, a precise combination of natural fibre and polymer can enhance the thermal stability.

3.3. Factor of Treatment. Lee et al. [43] investigated the viscoelastic behavior for Kenaf/Polylactic Acid (PLA) composites with a DMA test. The composites were pretreated by a silane coupling agent (SCA) in the amount of 1-5\%. SCA will undergo hydrolysis and condensation reactions to form silanol groups. This is a surface modification to link between the particles [44]. The authors found that the $E^{\prime}$ value from the DMA testing is getting lower when the temperature is rising. This is because chain fluidity has increased in the matrix. Yet the $E^{\prime}$ value becomes higher by increasing the coupling agent amount throughout the temperature. Besides this, the authors realised that the amount of kenaf content does affect the $E^{\prime}$ value of the experiment. The percentage of fibre content is directly proportional to its $E^{\prime}$ value until $70 \mathrm{wt} \%$ of fibre. The high quantity of kenaf fibre restricted the matrix amount. Hence, load transfer is difficult.

DSC measurement is also being conducted in research. From the results (Table 3), glass transition temperature, $T_{g}$, and melting temperature, $T_{m}$, were not influenced by the appearance of the silane coupling agent. However, both of the heat of fusion $\left(\Delta H_{f}\right)$ and the degree of crystalline $\left(X_{c}\right)$ had increased about $4 \mathrm{~J} / \mathrm{g}$ and $4 \%$, respectively. The increase of crystalline caused by the kenaf fibre was stimulated into heterogeneous crystallization.

Demir et al. [45] has used SCA and Maleic-anhydride Polypropylene (MAPP) to formulate the composites' flammability behaviour. MAPP creates an adhesive bridge for a better interface between fibres and matrixes [46]. As a result, MAPP modifications are able to reduce the LOI values more compared to SCA. However, TGA testing tells us that surface treatment has decreased the carbonaceous residue to $18 \%$ and $15 \%$, respectively for SCA and MAPP as compared to $24 \%$ residue for untreated composites. This may be due to the chemical altering reaction caused by the treatment component. Nevertheless, these treatments do enhance its tensile strength, young's modulus, and elongation ability.

On the other hand, Suharty et al. [47] have revealed TGA outcomes that are totally different. The DAP pretreatment on the fibre has dramatically lowered the temperature of the first thermodegradation moment, but it remains double/triple of char obtained at $500^{\circ} \mathrm{C}$ (Table 4). Yet the mechanical properties were nearly halved for all properties, such as compressive strength, wear ability, and tensile strength. 
TABLE 4: TGA date of composites [47].

\begin{tabular}{lcc}
\hline Composites & Temperature for 5\% weight lost $\left({ }^{\circ} \mathrm{C}\right)$ & $\mathrm{Char}$ at $500^{\circ} \mathrm{C}(\%)$ \\
\hline Neat PLA & 296 & 0.53 \\
Untreated coconut filter fibre/PLA & 265 & 5.96 \\
DAP-treated coconut filter fibre 1\%/PLA & 237 & 8.99 \\
DAP-treated coconut filter fibre 2.5\%/PLA & 226 & 9.30 \\
DAP-treated coconut filter fibre 5\%/PLA & 211 & 11.54 \\
Neat PP & 392 & 0.00 \\
Untreated coconut filter fibre/PP & 262 & 7.97 \\
DAP-treated coconut filter fibre 1\%/PP & 249 & 8.42 \\
DAP-treated coconut filter fibre 2.5\%/PP & 234 & 16.29 \\
DAP treated coconut filter fibre 5\%/PP & 221 & 18.31 \\
Untreated jute fibre/PP & 284 & 5.35 \\
DAP-treated jute fibre 1\%/PP & 247 & 11.28 \\
DAP-treated jute fibre 2.5\%/PP & 236 & 13.51 \\
DAP-treated jute fibre 5\%/PP & 226 & 16.43 \\
\hline
\end{tabular}

TABLE 5: Fire retardants and its function [34].

\begin{tabular}{l}
\hline Fire retardant \\
Phosphorous compounds \\
(i) Ammonium polyphosphate \\
(ii) Sodium phosphate \\
\hline Bromine Based compounds \\
Decabromodiphenyl oxide \\
Antimony based \\
Antimony trioxide
\end{tabular}

Metal hydroxides

(i) Aluminium-based

(ii) Magnesium-based

\section{Description}

(i) An swelling material, char formers and stop the fire propagation

(ii) Generation of solid form of phosphoric acid inhibits access to oxygen and shields it from releasing flammable gases able to feed flames

(i) Acts in the condensed phase to direct chemical reactions inside burning. Heavy-bromine gases cover the material from touching oxygen and heat

(ii) Always used with an antimony synergist, often antimony trioxide

The compounds alone do not work much, yet are powerful in combination with halogens forming antimony trihalide to scavenge free radicals and increase char formation

(i) An inorganic compound thus healthy and environmentally safe

(ii) More effective as hydrated compounds and provide effective flame retarding effects by releasing contained water at high temperatures, absorbing heat from the combustion zone, producing char, generating metal oxide coating that acts as insulator and reduces smoke (iii) $\mathrm{Mg}(\mathrm{OH})_{2}$ has superior endothermic flame retarding reaction and is more suitable for polyolefins, polypropylene, and polyamides because it decomposes at a higher temperature $\left(300-320^{\circ} \mathrm{C}\right)$, thus allowing it to be processed in plastics, for which $\mathrm{Al}(\mathrm{OH})_{3}$ (decomposition temperature: $200^{\circ} \mathrm{C}$ ) is not thermally stable enough

\begin{tabular}{ll}
\hline $\begin{array}{l}\text { Boron-based compounds } \\
\text { Zinc borate }\end{array}$ & (i) Are generally char producers. \\
\hline Melamine-based & (ii) Zinc borate compounds reduce smoke production and are mostly used as hydrates \\
Melamine cyanurate & (ii) The heat required from dehydration also contributes to its fire retardant capability
\end{tabular}

TABLE 6: TGA data of wood-fibre/PP composites [54].

\begin{tabular}{lccc}
\hline \multicolumn{2}{c}{$\begin{array}{c}\text { Flame retardant portion in wood/PP Sample } \\
\text { Ammonium polyphosphate }\end{array}$} & Temperature for 5\% weight lost $\left({ }^{\circ} \mathrm{C}\right)$ & $\mathrm{Char}$ at $600^{\circ} \mathrm{C}(\%)$ \\
\hline 0 & 0 & 383.39 & 2.96 \\
20 & 0 & 317.75 & 18.16 \\
20 & 2 & 314.06 & 21.05 \\
20 & 6 & 308.17 & 24.23 \\
20 & 10 & 298.78 & 26.46 \\
\hline
\end{tabular}




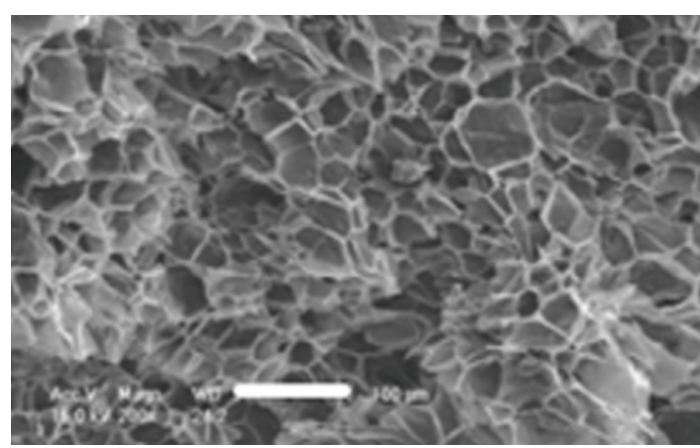

(a)

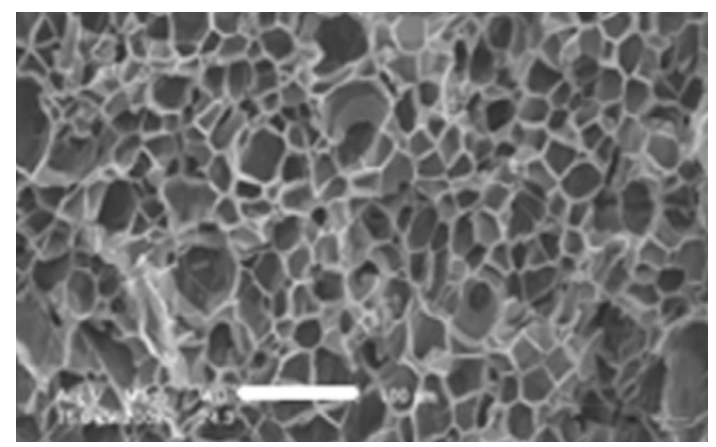

(b)

FIGURE 2: Scanning electron microscope (SEM) of surface structure of wood/PP composites with (a) 20\% APP flame retardant and (b) $20 \%$ APP \& $10 \%$ silica flame retardant [54].

3.4. Factor of $p H$ Differences. Mazuki et al. [30] found a different pattern of degradation dynamic mechanical properties for pultruded kenaf fibre reinforced composites when pretreated in different $\mathrm{pH}$ solutions. Three samples with $70 \%$ of kenaf fibre content were immersed in $\mathrm{pH} 5.5, \mathrm{pH}$, and $\mathrm{pH}$ 8.9, which represent acidic, neutral, and alkaline solutions, respectively, for 24 hours. The results show that the storage modulus of the sample was decreased after the immersion process. The values were reduced to $4 \mathrm{GPa}, 3.8 \mathrm{GPa}$, and $3 \mathrm{GPa}$ for $\mathrm{pH} 7, \mathrm{pH} 5.5$, and $\mathrm{pH} 8.9$ separately at their $T_{g}\left(172^{\circ} \mathrm{C}\right)$. The peak of $\tan \delta$ happened earlier and was reduced compared to the standard sample after the immersion process. The peak of $\tan \delta$ is the determination of $T_{g}$ [48]. The $T_{g}$ decreased from $172^{\circ} \mathrm{C}$ to $162^{\circ} \mathrm{C}, 155^{\circ} \mathrm{C}$ and $150^{\circ} \mathrm{C}$ for neutral, acidic and alkaline solution, respectively. These values are due to better ductility after the immersion process, caused by restricting the movement of polymer molecules $[49,50]$. As a conclusion, neither acidic nor alkaline conditions make composites work better than in normal conditions.

3.5. Factor of Fire Retardant Filler. Components like polymers and natural fibres are natural fire conductors. Thermal instability is a drawback of natural fibre polymer composites. Therefore a third element (FR) is added into the recipe to increase the composite's fire stability. Table 5 shows some FR groups and their ways of functioning.

Magnesium hydroxide $\left[\mathrm{Mg}(\mathrm{OH})_{2}\right]$ is the popular metal hydroxide FR for polymers due to its high endothermic nature and water yield behavior. The simple reaction starts at a very high temperature $\left(300-320^{\circ} \mathrm{C}\right)$ and is shown below (see [51]):

$$
\mathrm{Mg}(\mathrm{OH})_{2} \longrightarrow \mathrm{MgO}+\mathrm{H}_{2} \mathrm{O} \quad \Delta H=1.45 \mathrm{~kJ} / \mathrm{g}
$$

One research study has emulated FR's ability of $\mathrm{Mg}(\mathrm{OH})_{2}$ and zinc borate $[\mathrm{Zb}]$ on sawdust fibre and rice husk fibre reinforced with PP matrixes [52]. The author discovered that $\mathrm{Zb}$ is a good $\mathrm{FR}$, but $\mathrm{Mg}(\mathrm{OH})_{2}$ is even better at lowering the burning rate. Nevertheless, Jeencham et al. [53] haves used $\mathrm{Mg}(\mathrm{OH})_{2}$ and $\mathrm{Zb}$ as synergists with ammonium polyphosphate $[\mathrm{APP}]$ in a sisal/PP composite. The combination of
TABLE 7: Result of the flammability test [55].

\begin{tabular}{lccc}
\hline Sample & Ignition time(s) & Burnt area (\%) & Weight loss (\%) \\
\hline Untreated & 50 & 18.43 & 0.99 \\
DAP-treated & 100 & 15.83 & 0.97 \\
MAP-treated & 100 & 14.28 & 0.55 \\
BP-treated & 120 & 8.52 & 0.69 \\
\hline
\end{tabular}

APP/Zb fully protected the composite from burning and was classified as V-0 in the vertical burning test. Unfortunately, APP is not a good thermal stability agent. It has the lowest $5 \%$ weight lost temperature and char residue. As a conclusion of both papers, $\mathrm{Mg}(\mathrm{OH})_{2}$ gives the most thermal stability, $\mathrm{Zb}$ exhibits the most char residue, and APP reduces the burning rate the most.

Although APP has relatively poor thermal stability properties, Zhang et al. [54] took the challenge to integrate it with a silica synergistic agent. This TG result is shown in Table 6 and it did improve the char residue portion. Therefore, we can announce that silica is the most compatible synergistic agent rather than $\mathrm{Mg}(\mathrm{OH})_{2}$ and $\mathrm{Zb}$. This compatible agent result can be explained by looking at the morphological observation in Figure 2. As increases occurred in the portion of APP, some big cell sizes formed irregular shape and this disturbed the original formation of wood/PP particles. From Figure 2(b), silica agents reduce the size of big APP particles and thus maintain the structure of composites.

A fire ignition test was carried out in the laboratory by Izran et al. [55]. The sample is made of kenaf core particles with $180^{\circ} \mathrm{C}$ hot press. A few types of fire retardant filler added into the sample tend to get better results, such as monoammonium phosphate (MAP), diammonium phosphate (DAP), and a mixture of boric acid, guanylurea phosphate, and phosphoric acid (BP). Table 7 lists the results of the test. BP is able to extend its ignition period more than untreated board by doubling the time to 2 minutes. Besides, BP has the lowest of burnt area and the second least weight loss. BP shows good fire retardant behaviour and this agreed with the research carried out by Abdul Rashid and Chew [56]. 


\section{Summary}

Fire behaviour properties are significant factors for natural fibre based polymer composites in terms of safety. Kenaf fibre is the most well-known natural fibre option studied by researchers. Understanding its flammability factors and improving them will help to delay passenger panic and hence extend the escape time. Besides this, each fire analysis can detect different kinds of fire properties. By having TGA, it was found that the fire behaviour of composites tends towards fibre fire behavior when its proportion increases in composites. At the same time, storage modulus, $E^{\prime}$, and loss of modulus, $E^{\prime \prime}$, are increasing as well through DMA. Besides this, DSC analysis concluded that adding a coupling agent will have no effect on both glass transition temperature, $T_{g}$, and melting temperature, $T_{m}$. Thus, the flammability of a natural fibre PMC requires much research from many aspects, and kenaf fibre can be said to be one of the most highly recommended natural fibres in the world.

\section{Conflict of Interests}

The authors declare that there is no conflict of interests regarding the publication of this paper.

\section{References}

[1] J. Shaw, "A review of smoke and potential in-flight fire events in 1999," Tech. Rep. Doc 185, Society of Automotive Engineers, Washington, DC, USA, 2000.

[2] A. K. Chaturvedi, D. R. Smith, and D. V. Canfield, "Blood carbon monoxide and hydrogen cyanide concentrations in the fatalities of fire and non-fire associated civil aviation accidents, 1991-1998," Forensic Science International, vol. 121, no. 3, pp. 183188, 2001.

[3] Boeing, Statistical Summary of Commercial Jet Airplane Accidents: Worldwide Operations 1959-2004, 2005.

[4] Flight Safety Foundation, Aviation Safety Network on 24th May 2013, http://www.aviation-safety.net/database/ .

[5] E. R. Galea and N. C. Markatos, "A review of mathematical modelling of aircraft cabin fires," Applied Mathematical Modelling, vol. 11, no. 3, pp. 162-176, 1987.

[6] TheGuardianNews, "India Jet Crash Leaves More Than 150 Dead in Mangalore," 2013, http://www.guardian.co.uk/ world/2010/may/22/india-budget-airline-jet-deaths.

[7] Boeing Aero, "Flight and cabin crew response to inflight smoke," 2013, http://www.boeing.com/commerial/ aeromagazine/aero_14/inflight_story.html.

[8] T. Potter, M. Lavado, and C. Pellon, "Methods for characterizing arc fault signatures in aerospace applications, Texas instruments," 2013, http://www.sensata.com/download/ AgingAircraftConf-Sept2003.pdf.

[9] P. J. Herrera-Franco and A. Valadez-González, "Mechanical properties of continuous natural fibre-reinforced polymer composites," Composites Part A: Applied Science and Manufacturing, vol. 35, no. 3, pp. 339-345, 2004.

[10] H. M. Akil, M. F. Omar, A. A. M. Mazuki, S. Safiee, Z. A. M. Ishak, and A. Abu Bakar, "Kenaf fiber reinforced composites: a review," Materials and Design, vol. 32, no. 8-9, pp. 4107-4121, 2011.
[11] J. Summerscales, N. P. J. Dissanayake, A. S. Virk, and W. Hall, "A review of bast fibres and their composites. Part 1-fibres as reinforcements," Composites Part A: Applied Science and Manufacturing, vol. 41, no. 10, pp. 1329-1335, 2010.

[12] J. E. McIntyre, The Chemistry of Fibres, 6, Edward Arnold, 2009.

[13] M. M. Davoodi, S. M. Sapuan, D. Ahmad, A. Ali, A. Khalina, and M. Jonoobi, "Mechanical properties of hybrid kenaf/glass reinforced epoxy composite for passenger car bumper beam," Materials and Design, vol. 31, no. 10, pp. 4927-4932, 2010.

[14] J. A. Fuwape, "Paper from kenaf fibre," Bioresource Technology, vol. 43, no. 2, pp. 113-115, 1993.

[15] J. S. Han, W. Kim, and R. M. Rowell, "Chemical and physical properties of kenaf as a function of growth," in Proceedings of the 7th Annual International Kenaf Association Conference, pp. 63-83, Irving, Tex, USA, 1995.

[16] A. F. Kador, C. Karlgren, and H. Verwest, "Kenaf-a fast growing fibre source for papermaking," Tappi Journal, vol. 73, no. 11, pp. 205-209, 1990.

[17] M. S. Sajab, C. H. Chia, S. Zakaria et al., "Citric acid modified kenaf core fibres for removal of methylene blue from aqueous solution," Bioresource Technology, vol. 102, no. 15, pp. 7237-7243, 2011.

[18] K. Izran, A. Zaidon, A. M. A. Rashid et al., "Fire propagation and strength performance of fire retardant-treated Hibiscus cannabinus particleboard," Asian Journal of Applied Sceinces, vol. 2, no. 5, pp. 446-455, 2009.

[19] T. Seller Jr., G. D. Miller, and M. J. Fuller, "Kenaf core as a board raw material," Forest Products Journal, vol. 43, no. 7-8, pp. 69-71, 1993.

[20] C. S. Taylor, KenAf as a New Annual Fibre Source for industrial Uses: General Economic and environmental Aspects, vol. 13, Kenaf International, KI Pub, McAllen, Tex, USA, 1992.

[21] T. Nishino, K. Hirao, M. Kotera, K. Nakamae, and H. Inagaki, "Kenaf reinforced biodegradable composite," Composites Science and Technology, vol. 63, no. 9, pp. 1281-1286, 2003.

[22] C. Baillie, Green Composites: Polymer Composites and the Environment, CRC Press, Woodhead Publishing, Cambridge, UK, 2004

[23] G. Fisher, "Availability of kenaf fibres for the US paper industry," in Proceedings of the Pulping Conference, pp. 91-94, 1994.

[24] D. Rouison, M. Sain, and M. Couturier, "Resin transfer molding of natural fiber reinforced composites: cure simulation," Composites Science and Technology, vol. 64, no. 5, pp. 629-644, 2004.

[25] N. C. Kuchinda, W. B. Ndahi, S. T. O. Lagoke, and M. K. Ahmed, "The effects of nitrogen and period of weed interference on the fibre yield of kenaf (Hisbiscus cannabinus L.) in the northern Guinea Savanna of Nigeria," Crop Protection, vol. 20, no. 3, pp. 229-235, 2001.

[26] T. B. T. Lam and K. Liyama, "Structural details of kenaf cell walls and fixation of carbon dioxide," in Proceedings of the Abstract of the 2000 /International Kenaf Symposium, vol. 14, 2000.

[27] B. F. W. Rogowski, "The fire propagation test: its development and application," Fire Research Technical Paper 25, H. M. S. O., London, UK, 1970.

[28] A. Tewarson, "Flammability parameters of materials: ignition, combustion and fire propagation," Journal of Fire Sciences, vol. 12, pp. 329-355, 1994.

[29] N. M. Julkapli and H. M. Akil, "Thermal properties of kenaffilled chitosan biocomposites," Polymer-Plastics Technology and Engineering, vol. 49, no. 2, pp. 147-153, 2010. 
[30] A. A. M. Mazuki, H. M. Akil, S. Safiee, Z. A. M. Ishak, and A. A. Bakar, "Degradation of dynamic mechanical properties of pultruded kenaf fiber reinforced composites after immersion in various solutions," Composites Part B: Engineering, vol. 42, no. 1, pp. 71-76, 2011.

[31] X. Qu, A. Wirsén, and A.-C. Albertsson, "Effect of lactic/glycolic acid side chains on the thermal degradation kinetics of chitosan derivatives," Polymer, vol. 41, no. 13, pp. 4841-4847, 2000.

[32] B. Kandola, "Nanocomposites, Fire Retardant Materials," A. R. Horrocks, Ed., Woodhead Publishing, Cambridge, UK, 2000.

[33] Y. A. El-Shekeil, S. M. Sapuan, K. Abdan, and E. S. Zainudin, "Influence of fiber content on the mechanical and thermal properties of Kenaf fiber reinforced thermoplastic polyurethane composites," Materials and Design, vol. 40, pp. 299-303, 2012.

[34] Z. N. Azwa, B. F. Yousif, A. C. Manalo, and W. Karunasena, "A review on the degradability of polymeric composites base on natural fibres," Materals and Design, vol. 47, pp. 424-442, 2013.

[35] M. J. John, C. Bellmann, and R. D. Anandjiwala, "Kenafpolypropylene composites: effect of amphiphilic coupling agent on surface properties of fibres and composites," Carbohydrate Polymers, vol. 82, no. 3, pp. 549-554, 2010.

[36] D. De Britto and S. P. Campana-Filho, "A kinetic study on the thermal degradation of N,N,N-trimethylchitosan," Polymer Degradation and Stability, vol. 84, no. 2, pp. 353-361, 2004.

[37] S. Borysiak, D. Paukszta, and M. Helwig, "Flammability of wood-polypropylene composites," Polymer Degradation and Stability, vol. 91, no. 12, pp. 3339-3343, 2006.

[38] B. Li and J. He, "Investigation of mechanical property, flame retardancy and thermal degradation of LLDPE-wood-fibre composites," Polymer Degradation and Stability, vol. 83, no. 2, pp. 241-246, 2004.

[39] M. Helwig and D. Paukszta, "Flammability of composites based on polypropylene and flax fibers," Molecular Crystals and Liquid Crystals Science and Technology A: Molecular Crystals and Liquid Crystals, vol. 354, pp. 373-380, 2000.

[40] M. Helwig, D. Paukszta, J. Garbarczyk, and S. Borysiak, "Composites based on polypropylene and flax fibres: a study of fire performance and some physical and mechanical properties," in Proceedings from the 3rd International, Symposium on Natural Polymers and Composites (ISNaPol '00), Sao Pedro, Brazil, 2000.

[41] R. Kozłowski and M. Władyka-Przybylak, "Flammability and fire resistance of composites reinforced by natural fibers," Polymers for Advanced Technologies, vol. 19, no. 6, pp. 446-453, 2008.

[42] P. Russo, C. Carfagna, F. Cimino, D. Acierno, and P. Persico, "Biodegradable composites reinforced with kenaf fibre: thermal, mechanical, and morphological issues," Advances in Polymer Technology, vol. 32, pp. 313-322, 2012.

[43] B.-H. Lee, H.-S. Kim, S. Lee, H.-J. Kim, and J. R. Dorgan, "Bio-composites of kenaf fibers in polylactide: role of improved interfacial adhesion in the carding process," Composites Science and Technology, vol. 69, no. 15-16, pp. 2573-2579, 2009.

[44] D. Metin, F. Tihminlioğlu, D. Balköse, and S. Ülkü, "The effect of interfacial interactions on the mechanical properties of polypropylene/natural zeolite composites," Composites Part A: Applied Science and Manufacturing, vol. 35, no. 1, pp. 23-32, 2004.

[45] H. Demir, D. Balköse, and S. Ülkü, "Influence of surface modification of fillers and polymer on flammability and tensile behaviour of polypropylene-composites," Polymer Degradation and Stability, vol. 91, no. 5, pp. 1079-1085, 2006.
[46] M. Kazayawoko, J. J. Balatinecz, and L. M. Matuana, "Surface modification and adhesion mechanisms in woodfiberpolypropylene composites," Journal of Materials Science, vol. 34, no. 24, pp. 6189-6199, 1999.

[47] N. S. Suharty, I. P. Almanar, Sudirman, K. Dihardjo, and N. Astasari, "Flammability, biodegradability and mechanical properties of bio-composites waste polypropylene/ kenaf fibre containing nano $\mathrm{CaCO}_{3}$ with diammonium phosphate," Procedia Engineerin, vol. 4, pp. 282-287, 2012.

[48] W.-S. Kuo, T.-H. Ko, and H.-I. Chen, "Elastic moduli and damage mechanisms in 3D braided composites incorporating pultruded rods," Composites Part A: Applied Science and Manufacturing, vol. 29, no. 5-6, pp. 681-692, 1998.

[49] H. Gu, "Dynamic mechanical analysis of the seawater treated glass/polyester composites," Materials and Design, vol. 30, no. 7, pp. 2774-2777, 2009.

[50] A. K. Rana, B. C. Mitra, and A. N. Banerjee, "Short jute fiberreinforced polypropylene composites: dynamic Mechanical Study," Journal of Applied Polymer Science, vol. 71, no. 4, pp. 531$539,1999$.

[51] R. N. Rothon and P. R. Hornsby, "Flame retardant effects of magnesium hydroxide," Polymer Degradation and Stability, vol. 54, no. 2-3, pp. 383-385, 1996.

[52] M. Sain, S. H. Park, F. Suhara, and S. Law, "Flame retardant and mechanical properties of natural fibre-PP composites containing magnesium hydroxide," Polymer Degradation and Stability, vol. 83, no. 2, pp. 363-367, 2004.

[53] R. Jeencham, N. Suppakarn, and K. Jarukumjorn, "Effect of flame retardants on flame retardant, mechanical, and thermal properties of sisal fibre/polypropylene composites," Composites: Part B, vol. 56, pp. 249-253, 2014.

[54] Z. X. Zhang, J. Zhang, B.-X. Lu, Z. X. Xin, C. K. Kang, and J. K. Kim, "Effect of flame retardants on mechanical properties, flammability and foamability of PP/wood-fiber composites," Composites Part B: Engineering, vol. 43, no. 2, pp. 150-158, 2012.

[55] K. Izran, A. Zaidon, G. Beyer, A. A. Rashid, F. Abood, and S. Rahim, "Optimising treatment system for kenaf (Hibiscus cannabinus) Particleboard with fire retardants," Journal of Tropical Forest Science, vol. 22, no. 2, pp. 175-183, 2010.

[56] A. M. Abdul Rashid and L. T. Chew, "Fire retardant treated chipboards," in Proceeding Conference on Forestry and Forest Product Research, pp. 37-44, CFFPR, Forest Research Institute, Kuala Lumpur, Malaysia, 1990.

[57] United States Government General Accountability Office, "Aviations safety: status of FAA's actions to oversee the safety of composite airplanes," Report to Congressional Requesters GAO-11-849, 2011.

[58] P. Joseph and J. Ebdon, "Recent developments in flameretarding thermoplastics and thermosets," in Fire Retardant Materials, A. R. Horrocks, Ed., Woodhead Publishing, Cambridge, UK, 2000. 

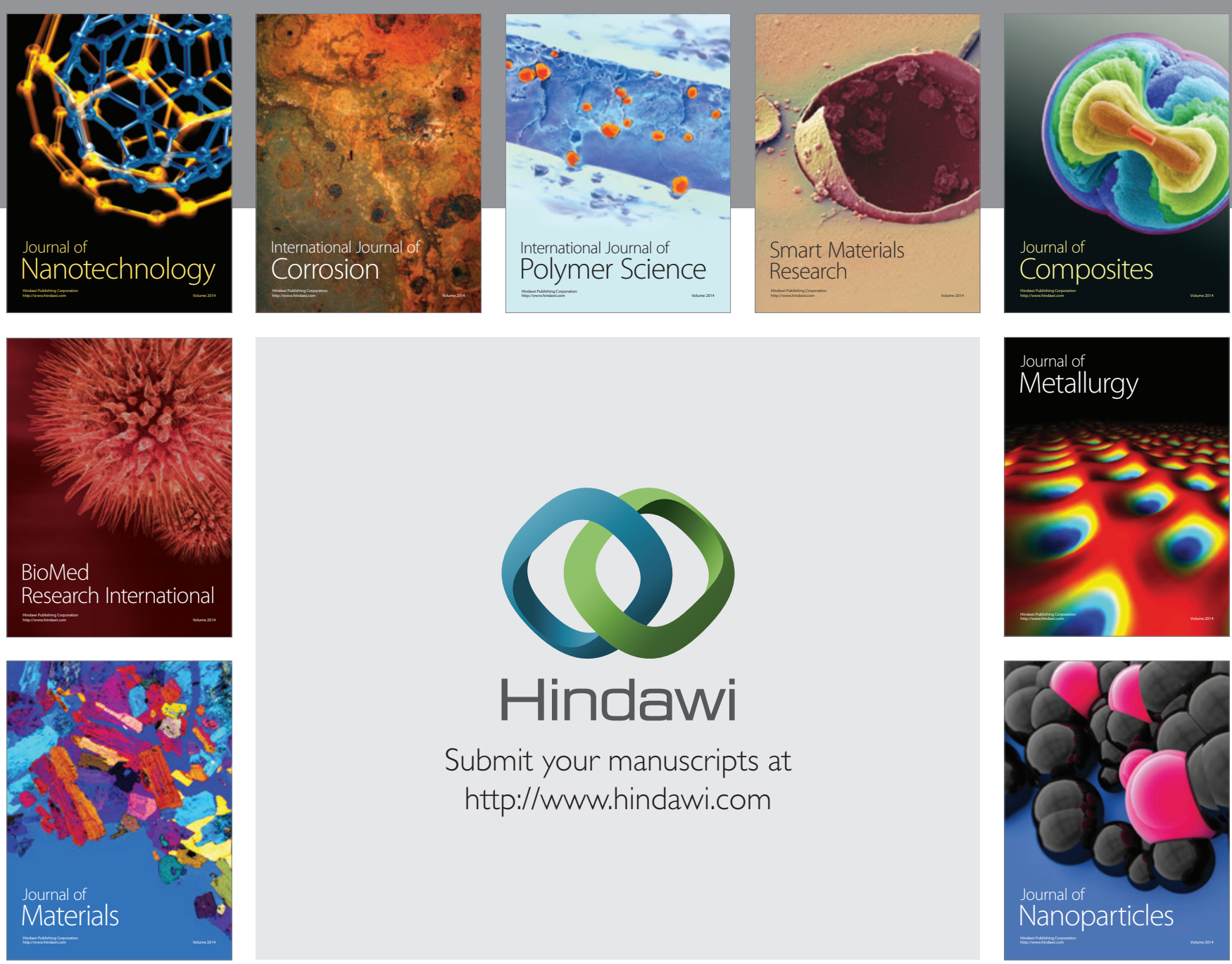

Submit your manuscripts at http://www.hindawi.com
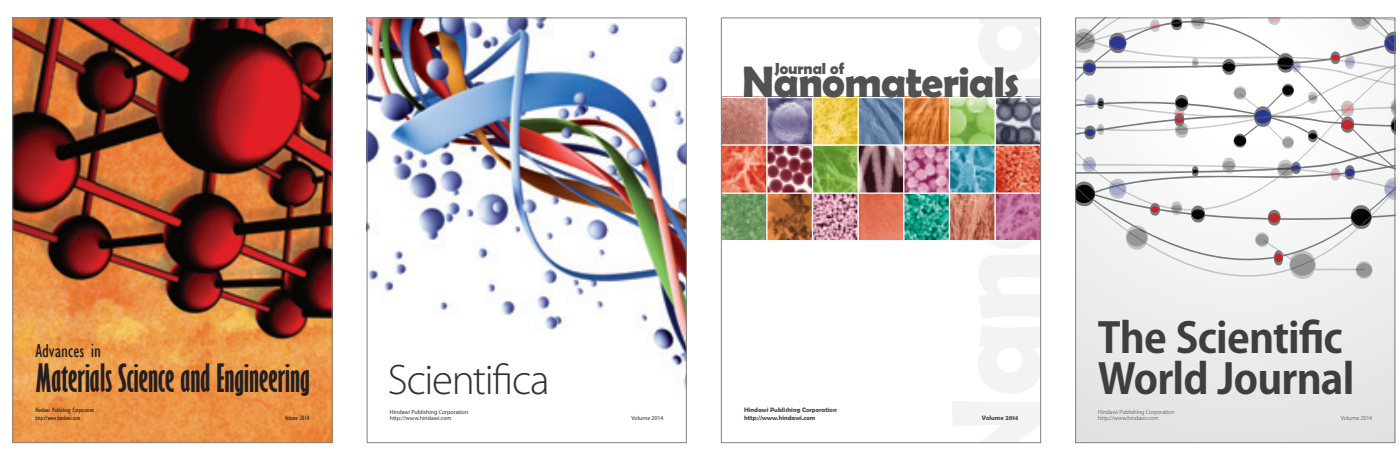

\section{The Scientific World Journal}
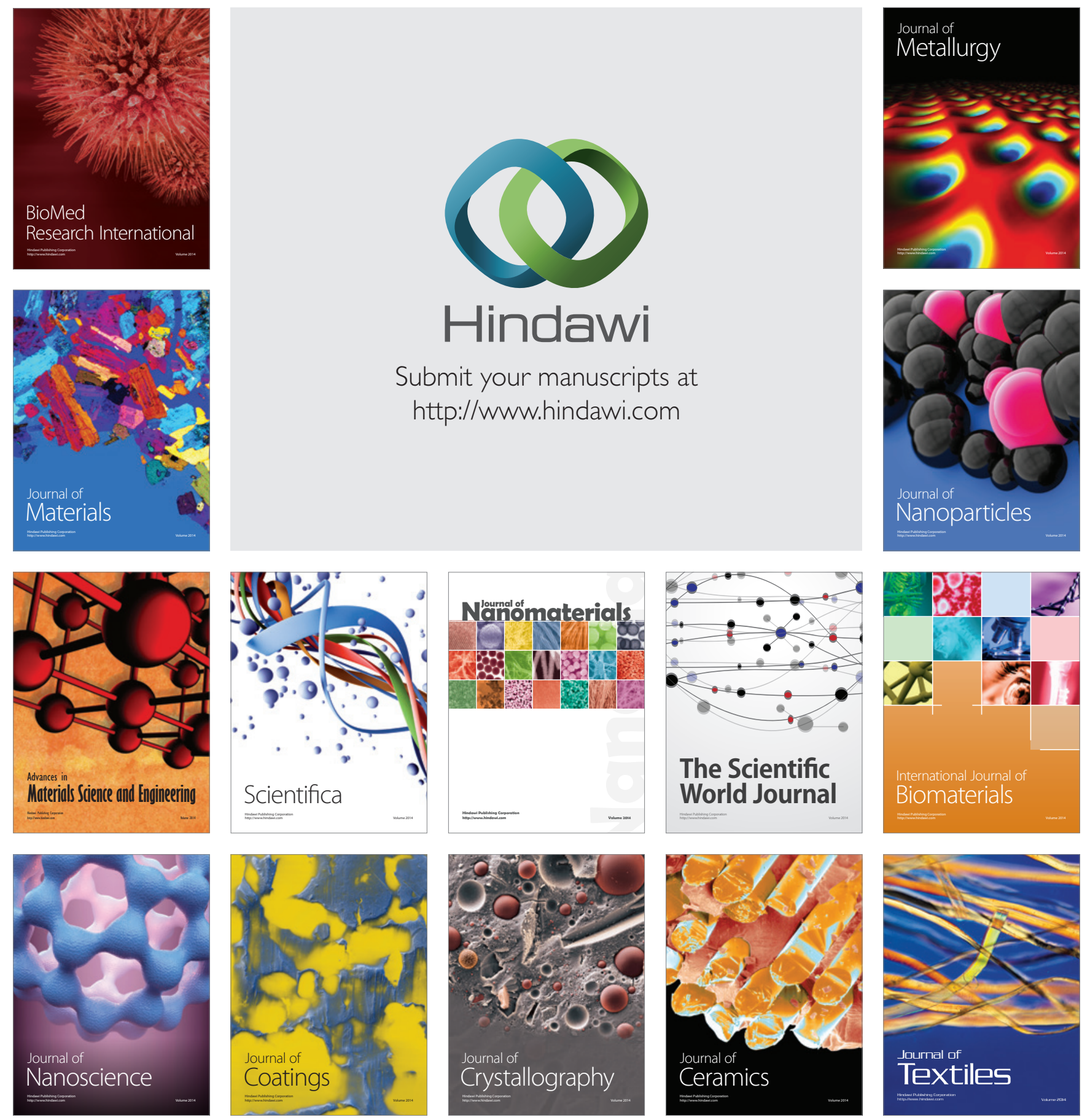